\title{
Effects of the midnight temperature maximum observed in the thermosphere-ionosphere over the northeast of Brazil
}

\author{
Cosme Alexandre O. B. Figueiredo ${ }^{1}$, Ricardo A. Buriti ${ }^{2}$, Igo Paulino ${ }^{2}$, John W. Meriwether ${ }^{3}$, Jonathan J. Makela ${ }^{4}$, \\ Inez S. Batista ${ }^{1}$, Diego Barros ${ }^{1}$, and Amauri F. Medeiros ${ }^{2}$ \\ ${ }^{1}$ Instituto Nacional de Pesquisas Espaciais, São José dos Campos, SP, Brazil \\ ${ }^{2}$ Unidade Acadêmica de Física, Universidade Federal de Campina Grande, Campina Grande, PB, Brazil \\ ${ }^{3}$ Department of Physics and Astronomy, Clemson University, Clemson, SC 29631, USA \\ ${ }^{4}$ Department of Electrical and Computer Engineering, University of Illinois at Urbana-Champaign, Urbana, IL 61801, USA
}

Correspondence to: Cosme Alexandre O. B. Figueiredo (anagetinga@gmail.com)

Received: 22 March 2017 - Revised: 30 June 2017 - Accepted: 14 July 2017 - Published: 17 August 2017

\begin{abstract}
The midnight temperature maximum (MTM) has been observed in the lower thermosphere by two Fabry-Pérot interferometers (FPIs) at São João do Cariri $\left(7.4^{\circ} \mathrm{S}, 36.5^{\circ} \mathrm{W}\right)$ and Cajazeiras $\left(6.9^{\circ} \mathrm{S}, 38.6^{\circ} \mathrm{W}\right)$ during 2011 , when the solar activity was moderate and the solar flux was between 90 and $155 \mathrm{SFU}\left(1 \mathrm{SFU}=10^{-22} \mathrm{~W} \mathrm{~m}^{-2} \mathrm{~Hz}^{-1}\right)$. The MTM is studied in detail using measurements of neutral temperature, wind and airglow relative intensity of OI630.0 nm (referred to as OI6300), and ionospheric parameters, such as virtual height $\left(h^{\prime} \mathrm{F}\right)$, the peak height of the F2 region $(h m \mathrm{~F} 2)$, and critical frequency of the $\mathrm{F}$ region $(f o \mathrm{~F} 2)$, which were measured by a Digisonde instrument (DPS) at Eusébio $\left(3.9^{\circ} \mathrm{S}, 38.4^{\circ} \mathrm{W}\right.$; geomagnetic coordinates $7.31^{\circ} \mathrm{S}, 32.40^{\circ} \mathrm{E}$ for 2011). The MTM peak was observed mostly along the year, except in May, June, and August. The amplitudes of the MTM varied from $64 \pm 46 \mathrm{~K}$ in April up to $144 \pm 48 \mathrm{~K}$ in October. The monthly temperature average showed a phase shift in the MTM peak around $0.25 \mathrm{~h}$ in September to $2.5 \mathrm{~h}$ in December before midnight. On the other hand, in February, March, and April the MTM peak occurred around midnight. International Reference Ionosphere 2012 (IRI-2012) model was compared to the neutral temperature observations and the IRI-2012 model failed in reproducing the MTM peaks. The zonal component of neutral wind flowed eastward the whole night; regardless of the month and the magnitude of the zonal wind, it was typically within the range of 50 to $150 \mathrm{~m} \mathrm{~s}^{-1}$ during the early evening. The meridional component of the neutral wind changed its direction over the months: from November to February, the meridional wind in the early evening flowed equatorward with a magnitude
\end{abstract}

between 25 and $100 \mathrm{~m} \mathrm{~s}^{-1}$; in contrast, during the winter months, the meridional wind flowed to the pole within the range of 0 to $-50 \mathrm{~m} \mathrm{~s}^{-1}$. Our results indicate that the reversal (changes in equator to poleward flow) or abatement of the meridional winds is an important factor in the MTM generation. From February to April and from September to December, the $h^{\prime} \mathrm{F}$ and the $h m \mathrm{~F} 2$ showed an increase around 18:00-20:00 LT within a range between 300 and $550 \mathrm{~km}$ and reached a minimal height of about $200-300 \mathrm{~km}$ close to midnight; then the layer rose again by about $40 \mathrm{~km}$ or, sometimes, remained at constant height. Furthermore, during the winter months, the $h^{\prime} \mathrm{F}$ and $h m \mathrm{~F} 2$ showed a different behavior; the signature of the pre-reversal enhancement did not appear as in other months and the heights did not exceed 260 and $350 \mathrm{~km}$. Our observation indicated that the midnight collapse of the F region was a consequence of the MTM in the meridional wind that was reflected in the height of the F region. Lastly, the behavior of the OI6300 showed, from February to April and from September to December, an increase in intensity around midnight or $1 \mathrm{~h}$ before, which was associated with the MTM, whereas, from May to August, the relative intensity was more intense in the early evening and decayed during the night.

Keywords. Ionosphere (equatorial ionosphere; ionosphereatmosphere interactions) - meteorology and atmospheric dynamics (thermospheric dynamics) 


\section{Introduction}

The tendency of the nighttime thermospheric temperature is to decrease. However, in the equatorial region around midnight the temperature increases by $50-200 \mathrm{~K}$ (e.g., characteristics observed at Arequipa, Peru, $16.2^{\circ} \mathrm{S} ; 71.5^{\circ} \mathrm{W}$; Faivre et al., 2006). This phenomenon is called the midnight temperature maximum (MTM) and has been the object of study since the 1970s through several instruments of observation, which are detailed in the review by Herrero et al. (1993).

The MTM signature is described by Behnke and Harper (1973) in the F region. Using an incoherent backscatter radar at Arecibo $\left(18.47^{\circ} \mathrm{N} ;-66.72^{\circ} \mathrm{W}\right)$, they showed that the decrease in the height of the $\mathrm{F}$ region was caused by the meridional wind. They also noted meridional wind flowing equatorward before midnight. Then the meridional wind diminishes and often reverses direction causing the downward motion of the F region (referred to as midnight collapse). Studies made in the Indian sector by Sastri and Rao (1994) and Sastri et al. (1994) found the same relationship among the MTM, thermospheric meridional wind, and $\mathrm{F}$ region height motion near midnight as observed by Behnke and Harper (1973) at Arecibo.

The airglow signature of the MTM is described by Colerico et al. (1996) and Burnside et al. (1981). They observed that when the equatorward meridional wind reverses or there is an abatement of the flow, the $\mathrm{F}$ region is drifted to lower heights, increasing the dissociative recombination of OI6300 (Link and Cogger, 1988).

The current understanding of the formation of the MTM is due to the results of the Whole Atmosphere Model (WAM) (Akmaev et al., 2009, 2010) and the National Center for Atmospheric Research Thermosphere Ionosphere Mesosphere Energetics Global Circulation Model (TIMEGCM) (Ma et al., 2010) that confirmed the theoretical explanation of MTM presented by Mayr et al. (1979) and Herrero et al. (1983). The formation of the MTM starts from the day-night pressure gradient that produces an eastward zonal wind toward the night terminator, combined with an upward propagation tidal meridional wind and thermospheric tidal wind produced in situ by EUV radiation at a subsolar point in the equatorial region, the so-called pressure bulge, and supports the development of a hydrostatic expansion. The hydrostatic expansion reverses the direction of the meridional wind to poles. This reversion causes the midnight collapse of the $\mathrm{F}$ region and the increase in the OI6300 relative intensity (Meriwether et al., 2011).

Biondi and Sipler (1985) made the first measurements of thermospheric wind and temperature in Brazil from August to September 1982. Then, Sahai et al. (1992) and Batista et al. (1997) studied the relation between the wind and the MTM at São José dos Campos $\left(23.2^{\circ} \mathrm{S}, 45^{\circ} \mathrm{W}\right)$ and Cachoeira Paulista $\left(22.5^{\circ} \mathrm{S}, 45.0^{\circ} \mathrm{W}\right)$. Twenty years later, the project entitled RENOIR (Makela et al., 2009) installed two Fabry-Pérot interferometers, an imaging system, and a
GPS receiver at São João do Cariri $\left(7.4^{\circ} \mathrm{S}, 36.5^{\circ} \mathrm{W}\right)$ and Cajazeiras $\left(6.9^{\circ} \mathrm{S}, 38.6^{\circ} \mathrm{W}\right)$ in order to study the equatorial thermosphere-ionosphere coupling. Several papers have been published: Chapagain et al. (2012) studied the relationship between Plasma bubbles and neutral wind; Makela et al. (2013) and Fisher et al. (2015) studied the neutral wind associated with the solar activity; Meriwether et al. $(2011,2013)$ compared the neutral temperature and wind to the recent model predictions.

The nighttime climatology of the MTM in the equatorial region is reported in the present work, based on Fabry-Pérot interferometer and Digisonde data from February to December 2011. The main goal of this study is to analyze the influences of the neutral winds along with the height and critical frequency of the $\mathrm{F}$ region on the development and dynamics of the MTM.

\section{Instrumentation and observations}

In this work, two Fabry-Pérot interferometers (FPIs), located at Cajazeiras and São João do Cariri, were used to measure thermospheric winds, temperature, and relative intensity of the OI6300 emission at $\sim 250 \mathrm{~km}$ height with an accuracy of $5-10 \mathrm{~m} \mathrm{~s}^{-1}$ and $20 \mathrm{~K}$ (Makela et al., 2009). Figure 1 shows the location of the observatories.

Each FPI consists of a $50 \mathrm{~mm}$ diameter interference filter with a $42 \mathrm{~mm}$ diameter etalon having a fixed-gap spacing of $1.5 \mathrm{~cm}$. The reflectivity of the etalon coating was specified to be $77 \%$ to enhance the transmission of the OI6300 emission without much loss of spectral resolution. A $30 \mathrm{~cm}$ focal length lens images 11.7 rings of the interference pattern onto an Andor Technology DU-434 CCD camera using a $1024 \times 1024$ CCD chip, with each square pixel having a dimension of $13 \mu \mathrm{m} \times 13 \mu \mathrm{m}$. The angular field of view for the outermost ring of the observed ring pattern is approximately $1.8^{\circ}$ (Meriwether et al., 2011; Makela et al., 2011).

In order to measure the airglow in a given region in the sky (zenith and geographic north, south, east, and west) with an elevation angle of $45^{\circ}$, a SkyScanner is placed above the FPI optics. The SkyScanner is a dual-mirror system controlled by two Animatics SmartMotors; one mirror rotates to vary the elevation angle and the other to change the azimuth angle. With this geometry of observation, the whole sky can be covered.

The absolute coordinate calibration of each axis is determined by using ephemeris of celestial objects (Sun, Moon, stars or planets) as the reference. An absolute pointing accuracy of approximately $0.2^{\circ}$ is typically achieved. More details of the instruments and analysis procedure used to estimate neutral winds can be found in Meriwether et al. (2011) and Makela et al. (2011).

The nighttime thermospheric winds are determined from the estimation of the Doppler shifts in the observed OI6300 interference pattern image. 


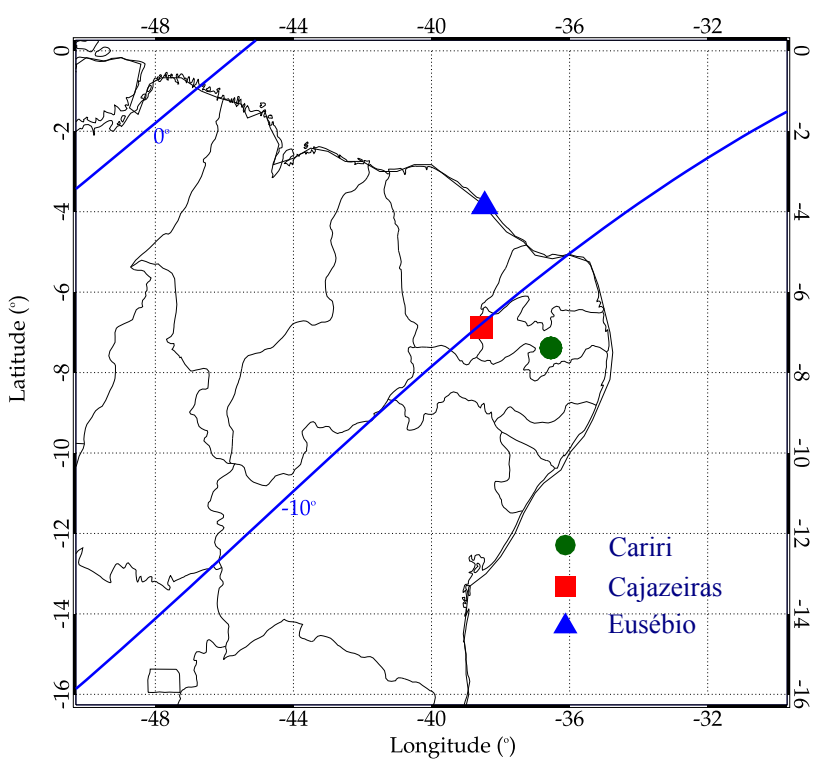

Figure 1. Map showing the geographic locations of the RENOIR instruments at São João do Cariri (green dot) and Cajazeiras (red box). The Digisonde is located at Eusébio (blue triangle). All instruments are in the Brazilian northeast. The blue solid lines denote the geomagnetic equator $\left(0^{\circ}\right)$ and $-10^{\circ}$ for 2011 .

The OI6300 is emitted by the excited oxygen atom in state $\mathrm{O}\left({ }^{1} \mathrm{D}\right)$ that decays to the ground state $\left({ }^{3} \mathrm{P}\right)$, spontaneously releasing the energy excess in an electromagnetic radiation form (Link and Cogger, 1988).

Data from a Digisonde portable sounder 4 (DPS-4) produced by the University of Massachusetts Lowell's Center for Atmospheric Research (UMLCAR) (Reinisch et al., 1997) were used in the present work as well. The ionosonde transmitter scans frequencies from 0.5 to $30 \mathrm{MHz}$ with a peak power of $500 \mathrm{~W}$. This instrument uses a crossed delta transmitting antenna and four crossed magnetic dipole receiving antennas (Reinisch et al., 1997; Batista et al., 2006). The DPS-4 basically operates vertically transmitting electromagnetic signals and measures the time lag until the echo is received. It generates a frequency versus height graph (ionograms), from which the vertical electron density profile from the reflecting layers can be calculated. The DPS-4 is located at Eusébio $\left(3.9^{\circ} \mathrm{S}, 38.4^{\circ} \mathrm{W}\right.$; geomagnetic coordinates $-7.31^{\circ} \mathrm{S}, 32.40^{\circ} \mathrm{E}$ for 2011 ) (Fig. 1), and it was used to provide the $\mathrm{F}$ region critical frequency $(f o \mathrm{~F} 2)$, peak height of the $\mathrm{F} 2$ region $(h m \mathrm{~F} 2)$, and its minimum virtual height $\left(h^{\prime} \mathrm{F}\right)$ (bottom-side $\mathrm{F}$ region).

Table 1 summarizes the conditions and MTM calculation used in this work. A total of 257 nights was included in the database for 11 months of observation, from February to December 2011. Table 1 also shows the averaged $F_{10.7}$ solar flux index and number of observed nights (temperature or wind) which were used in the monthly averages. The FPI measurements shown in Table 1 were obtained during the period from low to moderate solar activity based on the solar flux index, which ranged from $\sim 83 \mathrm{SFU}$, in February, to $\sim 141 \mathrm{SFU}$ in December $\left(1 \mathrm{SFU}=10^{-22} \mathrm{~W} \mathrm{~m}^{-2} \mathrm{~Hz}^{-1}\right)$. Table 1 shows the local time of the MTM peak and the respective amplitude relative to the shifted average International Reference Ionosphere 2012 (IRI-2012) temperature computed for each month (details on the next section).

The neutral temperature in all five directions (zenith, north, south, east and west) was averaged into half-hour bins for each month. The winds in the plots were classified into meridional and zonal components. Furthermore, there were observations in cardinal and common volume (CV) modes. These operational modes were presented and discussed by Makela et al. (2013). cardinal mode sets the FPI to look in the cardinal directions and measures the neutral wind and temperature. On the other hand, the CV mode sets both FPIs to look at the same point in the sky in three different views: north $\mathrm{CV}$, inline $\mathrm{CV}$, and south $\mathrm{CV}$. It also measures the components of the wind and temperature as well. In order to increase the amount of data and, therefore, calculate the monthly average, the meridional and zonal wind components are defined as the zonal component (cardinal east and west and $\mathrm{CV}$ zonal component) and the meridional component (cardinal north and south and CV meridional component). It was assumed that the variation in wind and temperatures regarding the observation modes and distances between stations $(\sim 230 \mathrm{~km})$ does not interfere with the calculation of the averages.

The weighted standard deviation was calculated for each half-hour bin, and they were associated with the statistical uncertainties of the method of analysis (Taylor, 1997). These uncertainties were inserted as error bars in the figures below; further details can be found in Makela et al. (2011, 2013).

The Digisonde continuously operated during 365 days in 2011. The temporal resolution of the measurements was $10 \mathrm{~min}$. Half-hour bins were used to average the measurements of the ionospheric parameters. The standard deviation of the averaged data in each half-hour bin was used as the uncertainty of the averages.

\section{Results and discussion}

\subsection{Identification of the MTM in the neutral and ionospheric parameters}

In order to clarify the signature of the MTM in the ionospheric and neutral parameters, Fig. 2 shows FPI and ionosonde measurements for two days: 26 June 2011 (without MTM) and 10 February 2011 (with MTM). On 10 February 2011 it was observed that the MTM causes a decrease in the velocities of the meridional and zonal wind component (Fig. 2a and b, right-hand panels) that propagate northward and eastward, respectively. Then, the $\mathrm{F}$ region started to decrease and reach the minimum height at about $200 \mathrm{~km}$ when 
Table 1. Summary of observations made with the FPIs. NA means not available.

\begin{tabular}{lrrrrr}
\hline Month & Number of nights & Averages of $F_{10.7}(\mathrm{SFU})$ & MTM time (LT) & MTM amplitude (K) & IRI shift (K) \\
\hline January 2011 & NA & 83.4 & NA & NA & NA \\
February 2011 & 23 & 94.5 & $23: 47$ & $77 \pm 32$ & 0 \\
March 2011 & 22 & 155.8 & $24: 10$ & $69 \pm 31$ & 0 \\
April 2011 & 112.5 & $23: 47$ & $64 \pm 46$ & 58 \\
May 2011 & 29 & 95.8 & NA & NA & -33 \\
June 2011 & 22 & 95.8 & NA & NA & -78 \\
July 2011 & 14 & $21: 40$ & $65 \pm 34$ & -90 \\
August 2011 & 21 & 101.7 & NA & NA & -90 \\
September 2011 & 29 & 134.5 & $23: 45$ & $65 \pm 38$ & 60 \\
October 2011 & 28 & 149.37 & $23: 30$ & $144 \pm 48$ & -87 \\
November 2011 & 25 & 153.46 & $23: 00$ & $83 \pm 27$ & 80 \\
December 2011 & 20 & 141.2 & $21: 50$ & $72 \pm 57$ & 60 \\
\hline
\end{tabular}

the MTM reaches the maximum peak (Fig. 2c). Lastly, an increase in the relative intensity of the OI6300 (Fig. 2d) and in the $f o \mathrm{~F} 2$ (Fig. 2c) was observed. On the other hand, on 26 June 2011, the MTM was not observed and the dynamic of the wind is totally different: the meridional wind flows poleward and the zonal wind velocity is not fast when compared to the day with MTM (10 February 2011). The behavior of the wind components did not cause the collapse of the F region and did not alter the relative intensity and the critical frequency of the F2 region.

Therefore, changes in the thermospheric meridional and zonal wind components affect the height of the $\mathrm{F}$ region and these changes affect the intensity of OI6300 associated with MTM. In sequence, we will describe and discuss these effects and the interplay of MTM for each neutral and ionospheric parameter through monthly averages.

\subsection{Neutral temperature and wind}

It is well known that the thermospheric neutral temperature decreases over night, as demonstrated in the neutral temperature model, IRI-2012 (Bilitza and Reinisch, 2008), shown in Fig. 3 (red line). However, during some months of the year, the observed neutral temperature (Fig. 3, black line) increases near midnight when compared to the empirical IRI2012 model (e.g., February). This anomalous behavior in the neutral temperature is known as MTM.

The IRI-2012 model does not reproduce the observed behavior of the MTM in temperature. This suggests that the model does not use temperature data observed from the equatorial region in its calculation.

The methodology applied to identify the MTM consists in comparing the observed temperature to the results modeled using IRI-2012. Initially, the modeled temperature was matched in the early evening (19:00-21:00 LT) with the observed temperature by applying a constant offset, as described by Meriwether et al. (2011). The magnitudes of these shifts are given in Table 1.
The MTM features, like shape, amplitude, and time of occurrence, are highly variable over a short period (day to day) as well as a long period (year to year, season to season, etc.) (Spencer et al., 1979; Bamgboye and McClure, 1982; Herrero and Spencer, 1982; Herrero et al., 1993; Emmert et al., 2006; Meriwether et al., 2011; Makela et al., 2013; Fisher et al., 2015; Tesema et al., 2017). The MTM peak is clearly observed during the whole year, except in May, June, and August. The amplitude of the MTM varies from $64 \pm 46 \mathrm{~K}$ in April up to $144 \pm 48 \mathrm{~K}$ in October.

The monthly temperature averages show a phase shift in the MTM peak of approximately $0.25 \mathrm{~h}$ in September to $2 \mathrm{~h}$ in December, before midnight. On the other hand, in February, March, and April the MTM peak occurs around midnight. The present results agree with the work done by Meriwether et al. (2011), which analyzed neutral temperature data for conditions of minimum solar activity during 2009 at $\mathrm{Ca}$ jazeiras.

The present and previous studies (Meriwether et al., 2011) carried out in the Brazilian northeast presents MTM amplitude between 40 and $144 \mathrm{~K}$, values that corroborate measurements made in the Peruvian (Meriwether, 2006; Faivre et al., 2006; Bamgboye and McClure, 1982) and equatorial East African longitude (Tesema et al., 2017) sectors, which present values between 50 and $200 \mathrm{~K}$ and between 30 and $110 \mathrm{~K}$, respectively. Studies made in the Indian sector by Sastri et al. (1994) and Sastri and Rao (1994) found that the MTM amplitudes between 80 and $570 \mathrm{~K}$, which are higher than the Peruvian, equatorial East African longitude, and Brazilian sectors.

The comparison of the temperature and the neutral meridional wind during the year (Figs. 4 and 5) reveals that the peak velocity flowing to the equator, approximately precedes the occurrence of MTM, or, in other words, the maximum in temperature occurs just after an equatorward peak in the meridional wind component, as can be seen in February to April and October to December. Otherwise, in winter months, the meridional wind flows to the pole and the peak of 


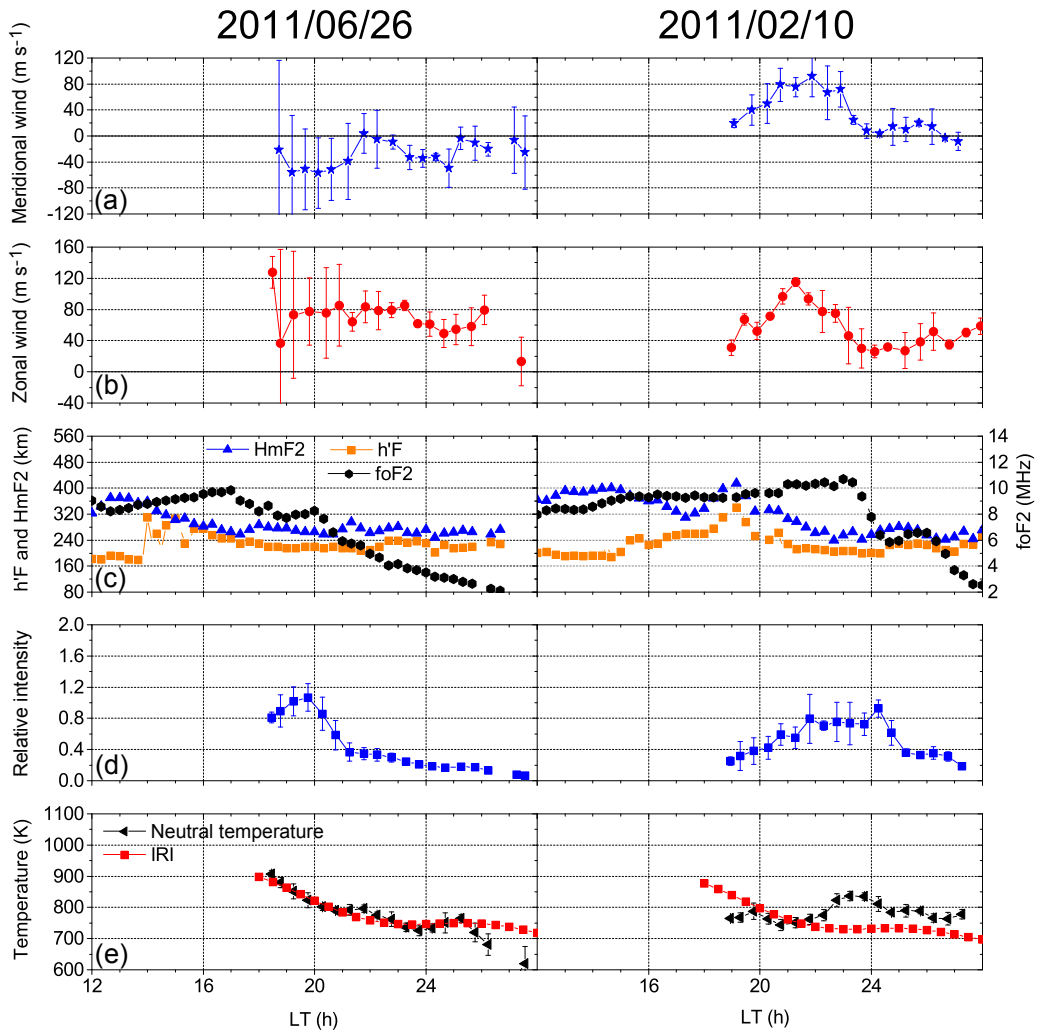

Figure 2. The meridional (a) and zonal (b) component of thermospheric neutral winds, $f \circ \mathrm{F} 2$ (c), $h^{\prime} \mathrm{F}$ (c), $h m \mathrm{~F} 2$ (c), relative intensity of OI6300 (d); the bottom panel (e) shows thermospheric neutral temperature with the averaged IRI-2012 curves, shifted to match the observed temperatures in the early evening. All these parameters were plotted for days without (26 June 2011) and with (10 February 2011) MTM. Positive values are northward and eastward. LT is UT -3.

MTM is not well pronounced. Fesen (1996) showed, by using the National Center for Atmospheric Research (NCAR) Thermosphere Ionosphere Electrodynamics General Circulation Model (TIEGCM), that the vertical propagation of the semidiurnal tide modes $(2,2)$ and $(2,3)$ interact with each other in summer (MTM is well pronounced) but not in winter (MTM is not well pronounced). It is well known that the meridional wind is very important to understand the equatorial thermosphere-ionosphere dynamic. For example, the meridional wind flowing to the equator is one of the mechanisms for the generation of MTM (Meriwether et al., 1986).

One can note that the minimum in meridional wind speed is around the MTM peak. The fact that the meridional wind flows equatorward is attributed to the combination of semidiurnal tides with higher-order harmonics (Akmaev et al., 2009). Meriwether et al. (2011) suggests that the location of the pressure bulge in the summer (from November to February) is due to the damping in the meridional wind before midnight. The pressure bulge is theoretically defined as the result of a nonlinear interaction in situ between the modulation of the diurnal electron density forced by EUV radiation absorption and higher tidal modes of the thermospheric winds (Herrero and Meriwether, 1980; Mayr et al., 1979).
In the winter solstice (from May to August), the pressure bulge is shifted to the north in subsolar latitude, and a decrease in the trans-hemispheric meridional wind around occurs midnight, as can be observed in Fig. 4. However, during the winter months we cannot observe the MTM peaks when compared with summer months. This is likely due to the poleward meridional wind propagation.

In general, the zonal wind (Fig. 5) flows eastward during the whole night, regardless of the month, as already observed by Meriwether et al. (2011). However, the zonal wind leaves a signature around midnight characterized by the occurrence of a minimum speed. According to Herrero et al. (1993) and Wharton et al. (1984), this minimum speed is associated with the passage of the pressure bulge from the equator to poles.

Meriwether et al. (2013) compared neutral temperature measurements observed by FPI to the Whole Atmosphere Model (WAM) (Akmaev et al., 2009). They observed that the WAM model predicts MTM peaks from 50 to $100 \mathrm{~K}$ in agreement with the observed FPI data. However, the model shows MTM peaks during the winter that were not evident in the neutral temperature. The WAM simulations have confirmed that the terdiurnal tide is a fundamental parameter to 

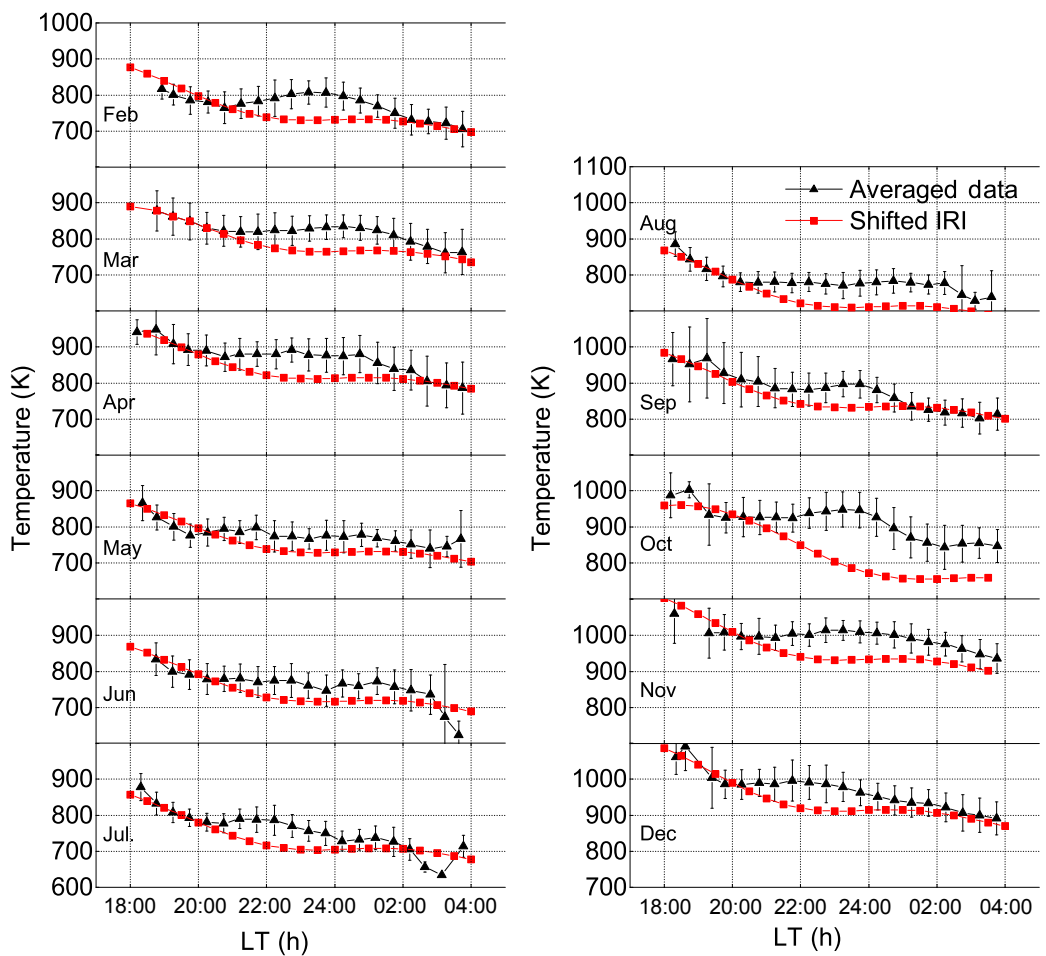

Figure 3. Monthly averaged temperature observed from February to December 2011 (black triangles). The averaged IRI curves, shifted to match the observed temperatures in the early evening (red squares).
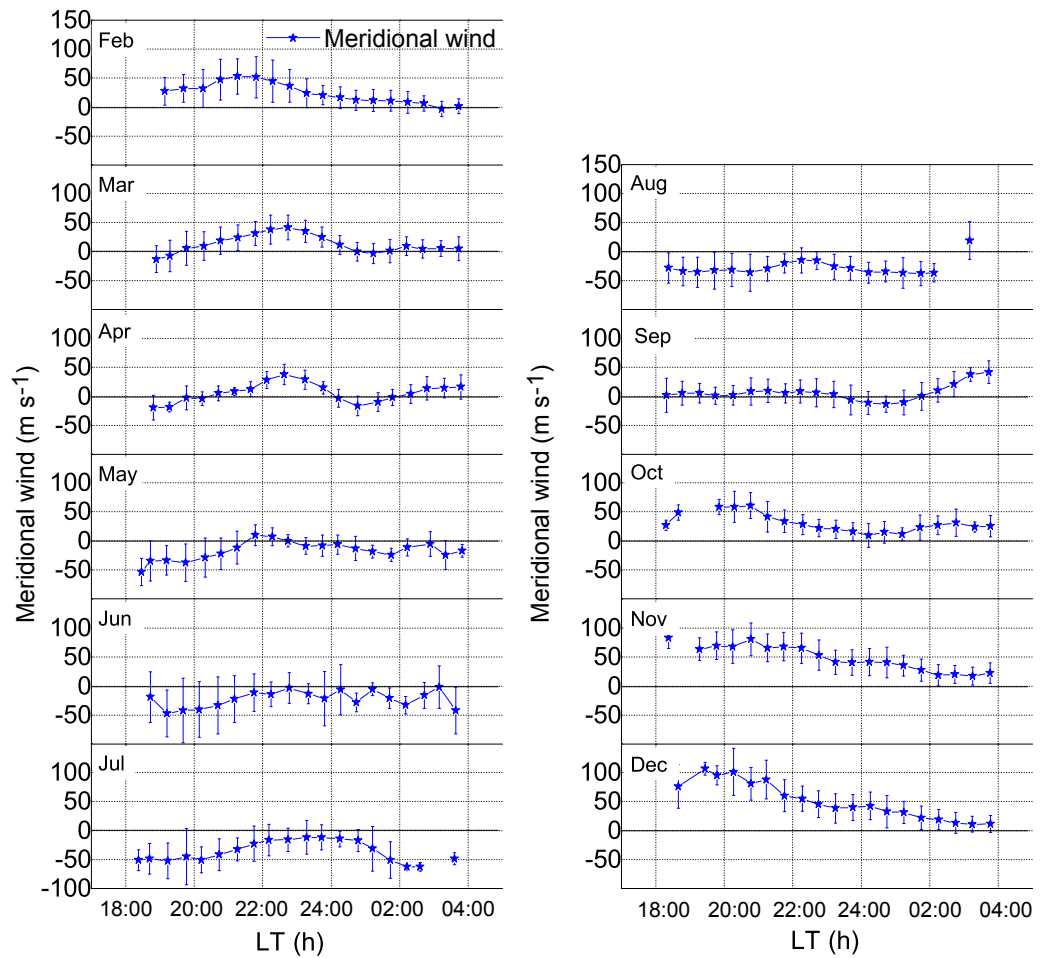

Figure 4. Monthly average of the meridional component of thermospheric neutral wind. Positive values are northward. LT is UT -3 . 

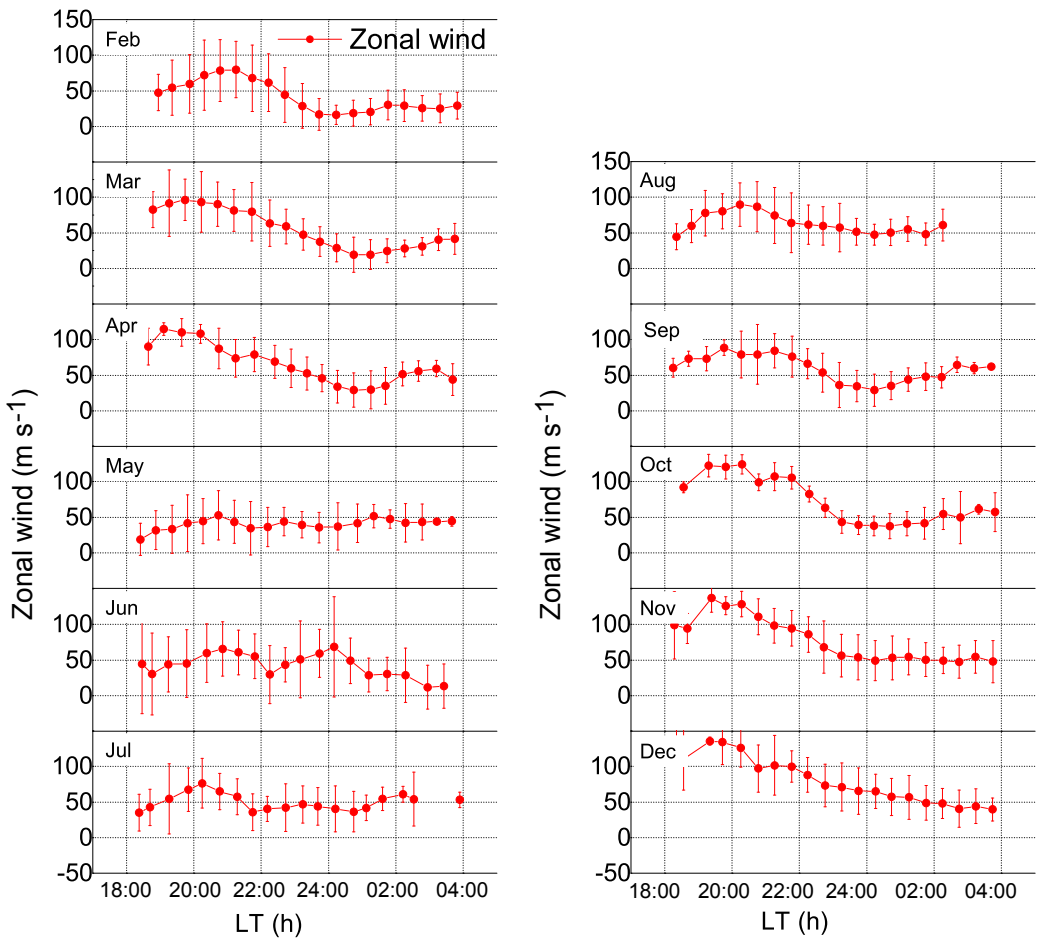

Figure 5. Monthly average of the zonal component of thermospheric neutral wind. Positive values are eastward. LT is UT -3 .

realistically describe the MTM (Mayr et al., 1979; Akmaev et al., 2008, 2009).

\subsection{Height of the $\mathrm{F}$ region and $f \circ \mathrm{F} 2$}

Monthly averages of ionosonde data from a low-latitude station were also used to study the vertical movement of the $\mathrm{F}$ region with values of the ionospheric parameters such as $h^{\prime} \mathrm{F}, h m \mathrm{~F} 2$, and $f o \mathrm{~F} 2$, which are shown in Fig. 6, in order to show the signature of the MTM peak in the ionospheric parameters. Note that the data are plotted between 12:00 and 04:00 LT, to show the behavior of the F region during the transition between day and night, e.g., the pre-reversal enhancement (PRE), and to verify whether it is related to the MTM phenomenon. The PRE is basically defined as an enhancement of the $\mathrm{F}$ region zonal electric field that occurs after the sunset due to the development of the F region dynamo. The enhanced eastward electric field is responsible for the enhancement in $\mathrm{F}$ region vertical plasma drift observed at equatorial and low-latitude stations; more details are found in Rishbeth (1971). However, when the PRE was compared to the MTM peaks, no clear correlation was observed between them and they will not be discussed further.

From February to April and from September to December, the $h^{\prime} \mathrm{F}$ and the $h m \mathrm{~F} 2$ shows an increase at about 18:0020:00 LT within a range between 300 and $550 \mathrm{~km}$; it reaches its minimal height at about $200-300 \mathrm{~km}$ close to midnight; then the layer rises again, by about $40 \mathrm{~km}$, or sometimes remains at constant height. It is important to note that the minimum height starts at 23:00 LT in February and it happened later, around 24:00 LT, in April. On the other hand, in September the minimum height occurred around 24:00 LT, and in December it was around 22:45 LT. These characteristics showing seasonality on the minimum height are in agreement with the seasonality of the MTM described by Herrero and Spencer (1982). The authors attributed this variation on time to semidiurnal and high-order tides that are enhanced in summer; thus, these tides make the nighttime temperature oscillates more rapidly in summer than in winter.

Furthermore, from May to August, the $h^{\prime} \mathrm{F}$ and $h m \mathrm{~F} 2$ showed a different behavior; the signature of the PRE in the $h^{\prime} \mathrm{F}$ and the $h m \mathrm{~F} 2$ heights did not appear as in other months, and the height does not exceed 260 and $350 \mathrm{~km}$. Batista et al. (1986) showed that, during the winter, the signature of the PRE in the F region height occurs later, around 20:00 LT, and presents a small vertical drift displacement for this period (around $20 \mathrm{~m} \mathrm{~s}^{-1}$ ). The behavior of the $\mathrm{F}$ region observed in the Brazilian sector during the winter corroborates studies using data obtained in the Indian sector (e.g., Niranjan et al., 2006; Srirama Rao et al., 1991).

The midnight collapse of the F region is an MTM consequence in the meridional wind that is reflected in the height of the F region. It is often observed at low latitudes, such as in Arecibo (Nelson and Cogger, 1971; Behnke and Harper, 1973; Burnside et al., 1981, 1983) and the Indian sector (Sastri et al., 1994; Sastri and Rao, 1994). Similar characteristics were also observed in the present study. Behnke and Harper 

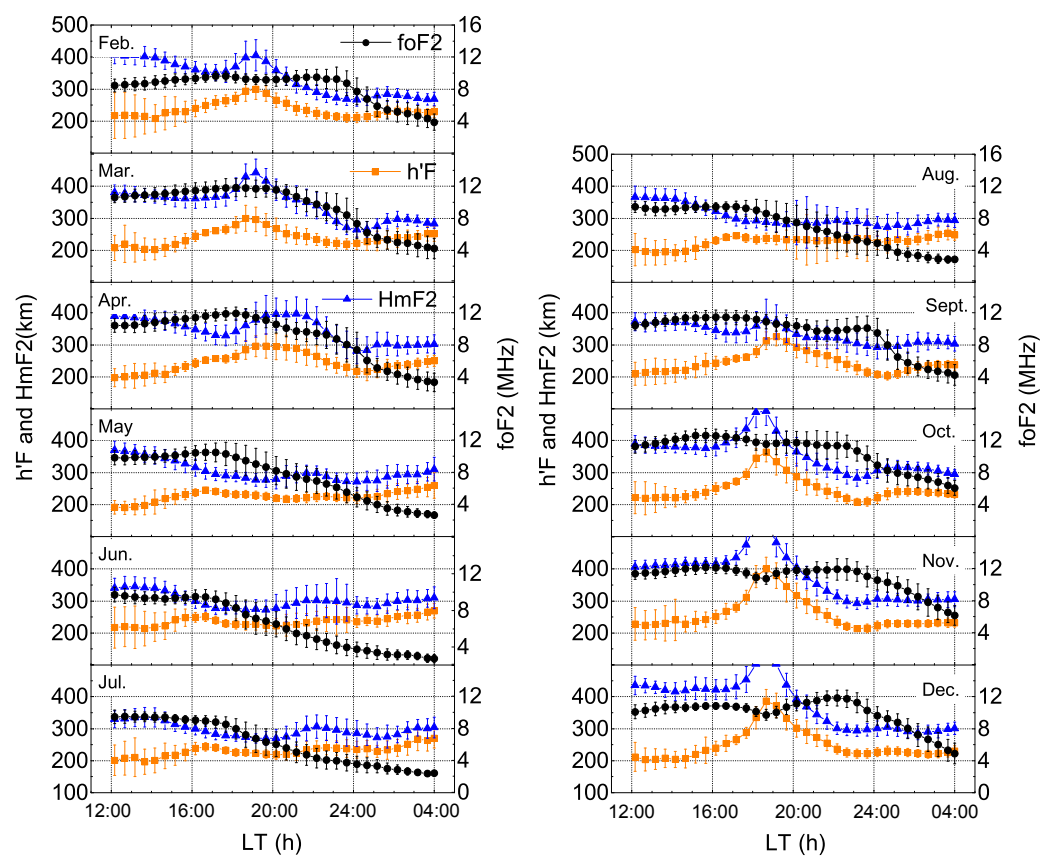

Figure 6. Monthly average of the minimum virtual height of the F region ( $h^{\prime} \mathrm{F}$ - orange square), the critical frequency of F2 region $(f \circ \mathrm{F} 2$ black circle) and the height maximum of the $\mathrm{F} 2$ region $(h m \mathrm{~F} 2$ - blue triangle $)$. LT is $\mathrm{UT}-3$.

(1973) and Harper (1973) demonstrated that the cause of the decrease in the $\mathrm{F}$ region was the propagation of the pressure bulge that produced the reversal in the thermospheric meridional wind component. Herrero et al. (1993) perceived that just a simple meridional wind abatement is necessary for the collapse to occur. Therefore, the variation in the meridional wind influences the morphology of the $\mathrm{F}$ region due to latitudinal and longitudinal displacement of the bulge pressure, corroborating our data.

Furthermore, the zonal wind is an important contributor for the height of the $\mathrm{F}$ region due to the large value of the magnetic declination at São João do Cariri and Cajazeiras $\left(\sim 22^{\circ} \mathrm{W}\right.$ for 2011$)$. Thus, the zonal wind can play a leading role in the understanding of ionospheric equatorial processes that influences the ion drag and vertical plasma motion (Anderson and Roble, 1981, 1974). This is because the zonal wind acts in the $\mathrm{F}$ region dynamo and may drive Pedersen currents favoring the appearance of a vertical polarization electric field that forces the plasma flows with the same velocity of the neutral wind (Rishbeth, 1971; Biondi et al., 1991).

Regarding the critical frequency (also shown in Fig. 6), from February to April and from September to December, there were small increments during the afternoon before the signature of the PRE in the F region heights. During the signature of the PRE in the F region heights, the $f o \mathrm{~F} 2$ diminished a little (as expected from the equatorial fountain effect, which transports ionization from equatorial to low latitudes); afterwards, it increased again with the maximum of one or
$2 \mathrm{~h}$ before midnight. Sometimes this second maximum is bigger than the first one. Lastly, the $f o \mathrm{~F} 2$ decreases after the second maximum and reaches the minimum values of about 4$6 \mathrm{MHz}$. From May to August, the foF2 shows a small increment reaching the maximum around 16:00-18:00 LT; then, it decreases to the minimum values $(2-4 \mathrm{MHz})$ at dusk.

From May to August, it was observed that $f o \mathrm{~F} 2$ decreases after 18:00 LT, and the parameters $h^{\prime} \mathrm{F}$ and $H m \mathrm{~F} 2$ were between 200 and $300 \mathrm{~km}$ of altitude. This behavior is to be expected because the rate of loss of electronic density is high for altitudes between 200 and $300 \mathrm{~km}$ (Liu et al., 2013). On the other hand, from September to December and in February there was a small decrease in $f o \mathrm{~F} 2$ in the PRE period, which, for a short period of time, returned to growth. As suggested by Liu et al. (2013), this behavior during the PRE period is due to the upward vertical drift that pushes the plasma to high altitudes where the recombination rate is insignificant, whereas in low altitudes the electronic density decreases significantly.

During March and April the $f o \mathrm{~F} 2$ decreased after the PRE period and near midnight a small enhancement appeared, i.e., a combination of the characteristics presented from May to August with the characteristics presented from September to December and February, suggesting that there is a precondition required for the enhancement of the $f_{o} \mathrm{~F} 2$ after the PRE period. Liu et al. (2013) associated the increase in $f o \mathrm{~F} 2$ after the PRE period to the westward electric field inducing vertical drift, concluding that downward drift is essential for the increase in the second peak of $f o \mathrm{~F} 2$. This increase occurs af- 

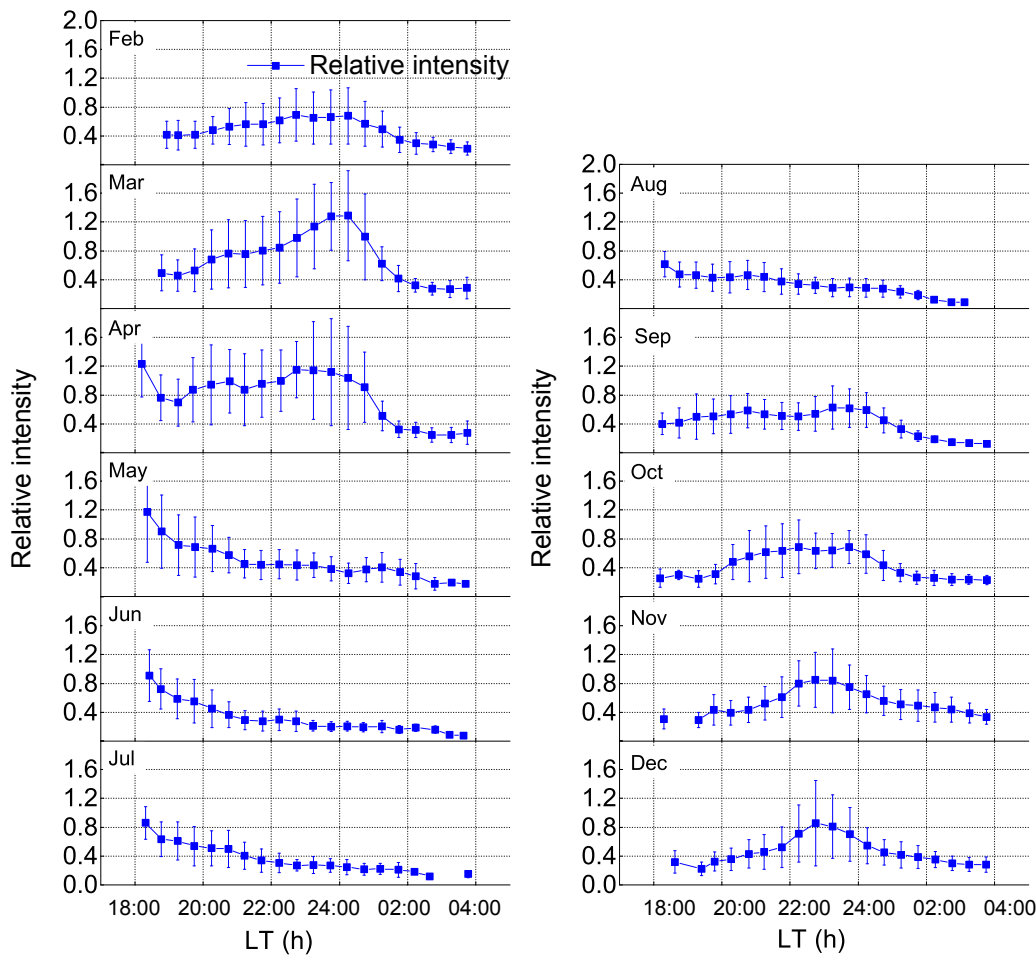

Figure 7. Monthly average of the OI630 $\mathrm{nm}$ relative intensity. LT is UT -3 .

ter midnight at Sanya, China $\left(18.24^{\circ} \mathrm{N} ; 109.50^{\circ} \mathrm{E}\right)$, and at Eusébio it occurs before midnight.

\subsection{Relative intensity}

Figure 7 shows the relative intensity of atomic oxygen emission (OI6300) observed in 2011. From February to April and from September to December, the behavior shows an increase in intensity around midnight or $1 \mathrm{~h}$ before, whereas, from May to August, the relative intensity is at a maximum in the early evening and decays during the night.

The dominant ion in the $\mathrm{F}$ region is the $\mathrm{O}+$, and its recombination rate is low during the night, whereas the height of the F region is kept constant (Cogger et al., 1974). When the meridional and zonal wind push down the $\mathrm{F}$ region in subtropical latitudes due to the pressure bulge associated with MTM for regions with high recombination $(h \leq 300 \mathrm{~km})$, the airglow emission will increase (Colerico et al., 1996).

It is possible to observe this behavior in the airglow associated with the midnight collapse of the $F$ region in the summer and some equinox months observed in Fig. 6. The low values of relative intensity of OI6300 at the beginning and the end of the night are associated with the well-known increase in the F region vertical drift (PRE) and with low density, respectively. During the winter, the relative intensity decreases throughout the night because of little variation in height as explained in the previous section.

\section{Summary}

In summary, we have presented a comprehensive data set of measurements from February to December 2011 of the thermospheric neutral winds and temperatures using two FabryPérot interferometers and $h^{\prime} \mathrm{F}, f o \mathrm{~F} 2$, and $h m \mathrm{~F} 2$ measured by a Digisonde, which operated in the Brazilian northeast during the increasing phase of the solar cycle.

The present study showed an MTM amplitude between 40 and $144 \mathrm{~K}$; these values were similar to other observations in the South American sector and differ from the Indian Sector.

The MTM also brought a specific signature in the neutral wind, $h^{\prime} \mathrm{F}, f o \mathrm{~F} 2, h m \mathrm{~F} 2$, and relative intensity of OI6300 to the equinoxes and summer solstice months as follows. The meridional and zonal neutral wind velocities decrease, arising from pressure bulge. Then the $\mathrm{F}$ region reaches the minimum height, and the relative intensity and $f o \mathrm{~F} 2$ increases. In contrast, during the winter, the MTM peak is not clearly evident. This may be due to the dynamics of the wind; the meridional wind does not flow toward the equator and the speed of the zonal wind is smaller than in the summer months. As a result the midnight collapse of the $\mathrm{F}$ region does not occur and the relative intensity of OI6300 decreases during the night.

The measurements of thermospheric neutral wind and temperature and ionospheric parameters observed in this study showed the importance of the midnight pressure bulge on the modification of the nighttime equatorial thermosphere 
and support the MTM. Moreover, this work shows that the IRI-2012 model does not reproduce the MTM peaks in the equatorial region.

Data availability. The wind and neutral temperature data used in this study are freely available for use from the Madrigal database (see http://madrigal.haystack.mit.edu/madrigal/). Please contact Jonathan J. Makela (jmakela@illinois.edu) for further information about these data.

Competing interests. The authors declare that they have no conflict of interest.

Special issue statement. This article is part of the special issue "Space weather connections to near-Earth space and the atmosphere". It is a result of the $6^{\circ}$ Simpósio Brasileiro de Geofísica Espacial e Aeronomia (SBGEA), Jataí, Brazil, 26-30 September 2016.

Acknowledgements. This work was supported by Conselho Nacional de Desenvolvimento Científico e Tecnológico (CNPq) under contracts 451836/2017-0, 473473/2013-5, 301078/2013-0, 161894/2015-1, 478117/2013-2, 150569/2017-3, 47431/2013-0, $302920 / 2014-5,141823 / 2016-0$, and 470589/2012-4. Work at the University of Illinois was supported by National Science Foundation CEDAR grants ATM-0940253, AGS-1138998, and AGS1452291. Work at Clemson University was supported by the National Science Foundation CEDAR grant ATM-09040217. The authors also acknowledge Maria Goreti for the Digisonde data processing.

The topical editor, Jean-Pierre Raulin, thanks two anonymous referees for help in evaluating this paper.

\section{References}

Akmaev, R., Fuller-Rowell, T., Wu, F., Forbes, J., Zhang, X., Anghel, A., Iredell, M., Moorthi, S., and Juang, H.M.: Tidal variability in the lower thermosphere: Comparison of Whole Atmosphere Model (WAM) simulations with observations from TIMED, Geophys. Res. Lett., 35, L03810, https://doi.org/10.1029/2007GL032584, 2008.

Akmaev, R., Wu, F., Fuller-Rowell, T., and Wang, H.: Midnight temperature maximum (MTM) in Whole Atmosphere Model (WAM) simulations, Geophys. Res. Lett., 36, L07108, https://doi.org/10.1029/2009GL037759, 2009.

Akmaev, R., Wu, F., Fuller-Rowell, T., Wang, H., and Iredell, M.: Midnight density and temperature maxima, and thermospheric dynamics in Whole Atmosphere Model simulations, J. Geophys. Res.-Space, 115, A08326, https://doi.org/10.1029/2010JA015651, 2010.

Anderson, D. and Roble, R.: The effect of vertical $\boldsymbol{E} \times \boldsymbol{B}$ ionospheric drifts on F region neutral winds in the low-latitude thermosphere, J. Geophys. Res., 79, 5231-5236, 1974.
Anderson, D. and Roble, R.: Neutral wind effects on the equatorial F-region ionosphere, J. Atmos. Terr. Phys., 43, 835-843, 1981.

Bamgboye, D. and McClure, J.: Seasonal variation in the occurrence time of the equatorial midnight temperature bulge, Geophys. Res. Lett., 9, 457-460, 1982.

Batista, I., Abdu, M., and Bittencourt, J.: Equatorial F region vertical plasma drifts: Seasonal and longitudinal asymmetries in the American sector, J. Geophys. Res.-Space, 91, 12055-12064, 1986.

Batista, I. S., Sastri, J., De Medeiros, R., and Abdu, M.: Nighttime thermospheric meridional winds at Cachoeira Paulista $\left(23^{\circ} \mathrm{S}\right.$, $45^{\circ} \mathrm{W}$ ): Evidence for effects of the equatorial midnight pressure bulge, J. Geophys. Res., 102, 20059-20062, 1997.

Batista, I. S., Abdu, M., Souza, J., Bertoni, F., Matsuoka, M., Camargo, P., and Bailey, G.: Unusual early morning development of the equatorial anomaly in the Brazilian sector during the Halloween magnetic storm, J. Geophys. Res.-Space, 111, A05307, https://doi.org/10.1029/2005JA011428, 2006.

Behnke, R. A. and Harper, R. M.: Vector measurements of F region ion transport at Arecibo, J. Geophys. Res., 78, 8222-8234, 1973.

Bilitza, D. and Reinisch, B. W.: International reference ionosphere 2007: improvements and new parameters, Adv. Space Res., 42, 599-609, 2008.

Biondi, M., Meriwether, J., Fejer, B. G., Gonzalez, S., and Hallenbeck, D.: Equatorial thermospheric wind changes during the solar cycle: Measurements at Arequipa, Peru, from 1983 to 1990, J. Geophys. Res.-Space, 96, 15917-15930, 1991.

Biondi, M. A. and Sipler, D. P.: Horizontal and vertical winds and temperatures in the equatorial thermosphere: Measurements from Natal, Brazil during August-September 1982, Planet. Space Sci., 33, 817-823, 1985.

Burnside, R., Herrero, F., Meriwether, J., and Walker, J.: Optical observations of thermospheric dynamics at Arecibo, J. Geophys. Res.-Space, 86, 5532-5540, 1981.

Burnside, R., Walker, J., Behnke, R., and Gonzales, C.: Polarization electric fields in the nighttime F layer at Arecibo, J. Geophys. Res.-Space, 88, 6259-6266, 1983.

Chapagain, N. P., Makela, J. J., Meriwether, J. W., Fisher, D. J., Buriti, R. A., and Medeiros, A. F.: Comparison of nighttime zonal neutral winds and equatorial plasma bubble drift velocities over Brazil, J. Geophys. Res.-Space, 117, A06309, https://doi.org/10.1029/2012JA017620, 2012.

Cogger, L., Wickwar, V. B., and Carlson, H.: Combined airglow and incoherent scatter observations as a technique for studying neutral atmospheric variations, Radio Sci., 9, 205-210, https://doi.org/10.1029/RS009i002p00205, 1974.

Colerico, M., Mendillo, M., Nottingham, D., Baumgardner, J., Meriwether, J., Mirick, J., Reinisch, B., Scali, J., Fesen, C., and Biondi, M.: Coordinated measurements of $F$ region dynamics related to the thermospheric midnight temperature maximum, J. Geophys. Res.-Space, 101, 26783-26793, 1996.

Emmert, J., Faivre, M., Hernandez, G., Jarvis, M., Meriwether, J., Niciejewski, R., Sipler, D., and Tepley, C.: Climatologies of nighttime upper thermospheric winds measured by ground-based Fabry-Perot interferometers during geomagnetically quiet conditions: 1 . Local time, latitudinal, seasonal, and solar cycle dependence, J. Geophys. Res.-Space, 111, A12302, https://doi.org/10.1029/2006JA011948, 2006. 
Faivre, M., Meriwether, J., Fesen, C., and Biondi, M.: Climatology of the midnight temperature maximum phenomenon at Arequipa, Peru, J. Geophys. Res.-Space, 111, A06302, https://doi.org/10.1029/2005JA011321, 2006.

Fesen, C.: Simulations of the low-latitude midnight temperature maximum, J. Geophys. Res.-Space, 101, 26863-26874, 1996.

Fisher, D. J., Makela, J. J., Meriwether, J. W., Buriti, R. A., Benkhaldoun, Z., Kaab, M., and Lagheryeb, A.: Climatologies of nighttime thermospheric winds and temperatures from FabryPerot interferometer measurements: From solar minimum to solar maximum, J. Geophys. Res.-Space, 120, 6679-6693, 2015.

Harper, R.: Nighttime meridional neutral winds near $350 \mathrm{~km}$ at low to mid-latitudes, J. Atmos. Terr. Phys., 35, 2023-2034, 1973.

Herrero, F. and Meriwether, J.: 6300- $\AA$ airglow meridional intensity gradients, J. Geophys. Res.-Space, 85, 4191-4204, 1980.

Herrero, F. and Spencer, N.: On the horizontal distribution of the equatorial thermospheric midnight temperature maximum and its seasonal variation, Geophys. Res. Lett., 9, 1179-1182, 1982.

Herrero, F., Mayr, H., and Spencer, N.: Latitudinal (seasonal) variations in the thermospheric midnight temperature maximum: A tidal analysis, J. Geophys. Res.-Space, 88, 7225-7235, 1983.

Herrero, F., Spencer, N., and Mayr, H.: Thermosphere and F-region plasma dynamics in the equatorial region, Adv. Space Res., 13, 201-220, 1993.

Link, R. and Cogger, L.: A reexamination of the OI 6300 A nightglow, J. Geophys. Res.-Space, 93, 9883-9892, 1988.

Liu, L., Chen, Y., Le, H., Ning, B., Wan, W., Liu, J., and Hu, L.: A case study of postmidnight enhancement in F-layer electron density over Sanya of China, J. Geophys. Res.-Space, 118, 46404648, 2013.

Ma, R., Xu, J., Wang, W., Lei, J., Liu, H.-L., Maute, A., and Hagan, M. E.: Variations of the nighttime thermospheric mass density at low and middle latitudes, J. Geophys. Res.-Space, 115, A12301, https://doi.org/10.1029/2010JA015784, 2010.

Makela, J. J., Meriwether, J. W., Lima, J. P., Miller, E. S., and Armstrong, S. J.: The remote equatorial nighttime observatory of ionospheric regions project and the international heliospherical year, Earth Moon Planets, 104, 211-226, 2009.

Makela, J. J., Meriwether, J. W., Huang, Y., and Sherwood, P. J.: Simulation and analysis of a multi-order imaging Fabry-Perot interferometer for the study of thermospheric winds and temperatures, Appl. Optics, 50, 4403-4416, 2011.

Makela, J. J., Fisher, D. J., Meriwether, J. W., Buriti, R. A., and Medeiros, A. F.: Near-continual ground-based nighttime observations of thermospheric neutral winds and temperatures over equatorial Brazil from 2009 to 2012, J. Atmos. Sol.-Terr. Phy., 103, 94-102, 2013.

Mayr, H., Harris, I., Spencer, N., Hedin, A., Wharton, L., Porter, H., Walker, J., and Carlson, H.: Tides and the midnight temperature anomaly in the thermosphere, Geophys. Res. Lett., 6, 447-450, 1979.

Meriwether, J.: Studies of thermospheric dynamics with a FabryPerot interferometer network: A review, J. Atmos. Sol.-Terr. Phy., 68, 1576-1589, 2006.

Meriwether, J., Moody, J., Biondi, M., and Roble, R.: Optical interferometric measurements of nighttime equatorial thermospheric winds at Arequipa, Peru, J. Geophys. Res.-Space, 91, 5557$5566,1986$.
Meriwether, J., Makela, J., Huang, Y., Fisher, D., Buriti, R., Medeiros, A., and Takahashi, H.: Climatology of the nighttime equatorial thermospheric winds and temperatures over Brazil near solar minimum, J. Geophys. Res.-Space, 116, A04322, https://doi.org/10.1029/2011JA016477, 2011.

Meriwether, J., Makela, J., Fisher, D., Buriti, R., Medeiros, A., Akmaev, R., Fuller-Rowell, T., and Wu, F.: Comparisons of thermospheric wind and temperature measurements in equatorial Brazil to Whole Atmosphere Model Predictions, J. Atmos. Sol.-Terr. Phy., 103, 103-112, 2013.

Nelson, G. and Cogger, L.: Dynamical behaviour of the nighttime ionosphere at Arecibo, J. Atmos. Terr. Phys., 33, 1711-1726, 1971.

Niranjan, K., Brahmanandam, P., and Srivani, B.: Signatures of equatorial midnight temperature maximum as observed from in situ and ground-based ionospheric measurements in the Indian sector, J. Geophys. Res.-Space, 111, A07309, https://doi.org/10.1029/2005JA011386, 2006.

Reinisch, B., Haines, D., Bibl, K., Galkin, I., Huang, X., Kitrosser, D., Sales, G., and Scali, J.: Ionospheric sounding in support of over-the-horizon radar, Radio Sci., 32, 1681-1694, 1997.

Rishbeth, H.: Polarization fields produced by winds in the equatorial F-region, Planet. Space Sci., 19, 357-369, 1971.

Sahai, Y., Takahashi, H., Teixeira, N., Fagundes, P., Clemesha, B., and Bittencourt, J.: Observations of thermospheric temperatures at $23^{\circ}$ S, Planet. Space Sci., 40, 1545-1549, 1992.

Sastri, J. H. and Rao, H. R.: Optical interferometer measurements of thermospheric temperature at Kavalur $\left(12.5^{\circ} \mathrm{N}, 78.5^{\circ} \mathrm{E}\right)$, India, J. Atmos. Terr. Phys., 56, 775-782, 1994.

Sastri, J. H., Rao, H., Somayajulu, V., and Chandra, H.: Thermospheric meridional neutral winds associated with equatorial midnight temperature maximum (MTM), Geophys. Res. Lett., 21, 825-825, 1994.

Spencer, N., Carignan, G., Mayr, H., Niemann, H., Theis, R., and Wharton, L.: The midnight temperature maximum in the earth's equatorial thermosphere, Geophys. Res. Lett., 6, 444-446, 1979.

Srirama Rao, M., Ramesh, K., and Niranjan, K.: Nocturnal F-region vertical drifts over Waltair, Indian Journal of Radio and Space Physics, 20, 327-332, 1991.

Taylor, J.: Introduction to error analysis, the study of uncertainties in physical measurements, Vol. 1, University Science Books, New York, NY, 1997.

Tesema, F., Mesquita, R., Meriwether, J., Damtie, B., Nigussie, M., Makela, J., Fisher, D., Harding, B., Yizengaw, E., and Sanders, S.: New results on equatorial thermospheric winds and temperatures from Ethiopia, Africa, Ann. Geophys., 35, 333-344, https://doi.org/10.5194/angeo-35-333-2017, 2017.

Wharton, L., Spencer, N., and Mayr, H.: The Earth's thermospheric superrotation from Dynamics Explorer 2, Geophys. Res. Lett., 11, 531-533, 1984. 